\title{
Unorthodox Agreement in Turkish Copular Sentences
}

\author{
Seyyit Talha Bedir*
}

\begin{abstract}
Turkish verbs agree with subject in almost all cases. The same goes for the copular adjectival or nominal structures. However, if a nominal predicate is $2^{\text {nd }}$ or $1^{\text {st }}$ person whereas the subject is $3^{\text {rd }}$ person, agreement takes place with the predicate instead of the subject. Harley \& Ritter's (2002) well-known three-way feature system inspired many accounts in explaining different morphosyntactic behaviors of personal features. However, in this account I will try to develop an economical argument using solely one feature: [ref]. It correctly explains some phenomena that previous feature-dependent accounts fall short explaining the phenomena. Arguments on this paper mostly build up on work of Ince \& Aygen \& Aydın (2015) and Uzun (2006), spotting problems in their proposal and offering solutions based on a single feature.
\end{abstract}

Keywords. Turkish copula; agreement; nominal copular sentences; predicate agreement; non-canonical agreement

1. Introduction. In this article I will examine one unorthodox ${ }^{1}$ agreement pattern in Turkish copular sentences. Normally in Turkish, the verb always agrees with the subject in person and number. However, in the presence of a copula (Section 1 will discuss the existence of copula in Turkish), the agreement patterns might deviate from this. When the nominal predicate is either $1^{\text {st }}$ or $2^{\text {nd }}$ person and the subject is a $3^{\text {rd }}$ person DP, subject does not agree since predicate DP takes over the agreement.

The analysis I will present follows the approach assumed by Bejar \& Kahnemayipour (2017) and Ince et al. (2015). It is built on the operation Agree (Chomsky 2000). Agree is an operation between an uninterpretable feature (probe) and an interpretable feature of identical value (its goal) in probe's c-command domain. Uninterpretable features of the probe Agree with those of the closest goal as per Minimal Link Condition (MLC) and are eliminated before the phase is sent to Spell Out. In the minimalist program, the uninterpretable feature of the probe must be checked and eliminated before Spell Out for the sentence to be interpretable.

The remainder of this paper is organized as follows. In section 2, I lay out the background relevant to the discussion in this paper. In section 3, I present a brief review Turkish copula and how I annotate it throughout the paper. Section 4 summarizes how Ince et al. (2015) explain the nonstandard agreement in Turkish nominal copular structures and lays out four problems I detected in their account. Section 5 will address the analysis of Béjar \& Kahnemayipour (2017), which proposes an immaculate analysis to explain non-standard agreement in Eastern Armenian and Persian. In this section, I will also question applicability of this analysis to Turkish

\footnotetext{
* I am deeply thankful to my professors Prof. Ayşe Sumru Özsoy and Prof. Balkız Öztürk for their feedback to my paper. Author: Seyyit Talha Bedir, Bogazici University (stalhabedir@gmail.com, talha.bedir@boun.edu.tr).

${ }^{1}$ An anonymous reviewer questioned whether the term "unorthodox" is appropriate since DP2 agreement is quite common and well-studied in the literature. For the languages that show straightforward DP1 agreement pattern, DP2 agreement is generally called "non-canonical" as in Béjar \& Kahnemayipour (2017). The reason why I have called some of the agreement pattern "unorthodox" is that examples I will provide below constitute an exception to the "non-canonical" agreement laid out by Ince et al. (2015) and Uzun (2006).
} 
copular sentences. In section 6, I introduce my proposal for a minimalist account in terms of the feature [ref] and its strong or strengthened version [ref*] to put forward a solution to mentioned problems. And section 7 will be the conclusion.

2. Background. Within the generative grammar tradition Higgins's $(1973,1979)$ taxonomy provided the basis for subsequent work on copular clauses. In his works, Higgins $(1973,1979)$ identified four different copular sentence types: identificational (referential subject, identificational predicate), identity (referential subject and predicate), predicational (referential subject, predicational object) and specificational (superscriptional subject, specificational object). Each type is illustrated in (1).

\section{(1) a. Identificational}

That atom is a metal.

b. Identity (Equative)

Superman is Clark Kent.

c. Predicational

Ali is a linguistics student.

d. Specificational

The one who broke the eggs is him.

Heggie (1988a,b) provides an elegant, unified analysis for English in which she argues that all copular sentence types listed by Higgins can be derived from a single structure. One of the proposals in her work is that specificational structures are derived from topicalization of predicate complement in the predicational structures ${ }^{2}$. However, Mikkelsen (2005:8-9) argues that Heggie's predicate complement movement hypothesis produced ungrammatical sentences when an auxiliary modal was present in the structure. Heggie's proposal is not ruling out the following ungrammatical structure:

(2) *The teacher might John be.

Underlying structure: ${ }^{*}\left[\mathrm{CP}\right.$ the teacher ${ }_{j}\left[\mathrm{C}^{\prime} \operatorname{might}_{k}\left[\mathrm{TP} \mathrm{John}_{i} t_{k}\left[\mathrm{vP}\right.\right.\right.$ be $\left.\left.\left.t_{i} t_{j}\right]\right]\right]$

In (2), although the DP in the predicate complement position is topicalized to Spec-CP as per Heggie's model, the sentence ended up ungrammatical in English ${ }^{3}$. In her book Mikkelsen provides evidence from Danish to further supplement specificational and predicational being separate classes. Mikkelsen also argues that identificational copular clauses do not have a uniform semantics as opposed to other three clause structures. Consequently, Mikkelsen (2005) proposes tripartite distinction for copulas: equative, predicational and specificational.

2.1. NON-CANONICAL AGREEMENT. For binominal copular clauses like [NP1 BE NP2], it is observed in the literature that significant number of languages that canonically exhibit NP1 (first noun phrase) agreement also exhibit NP2 (second noun phrase) agreement under certain conditions. Whereas some languages like English and French show strict NP1 agreement, i.e., always agreeing with the first noun phrase, some languages like Spanish, Italian, Serbian, Persian and Turkish may show NP2 agreement. Agreement selection from some languages is shown in (3).

a. The teacher is me.

English, NP1 agreement

\footnotetext{
${ }^{2}$ This is not to say that the idea that specificational copular sentences are inverted predicational is originally Heggie's. Williams (1983) and Partee (1986) precede Heggie's works in that regard.

${ }^{3}$ In Heggie's (1988a,b) works sentences with modals like (2) are correctly accounted for under equative constructions. However, the construction in (2) is also derivable.
} 

b. El maestro soy yo. the teacher am I
c. Mo'allem man-am. teacher I-am
Spanish, NP2 agreement
Persian, NP2 agreement

One of the elaborate explanations for NP2 agreement comes from Heggie's (1988a) work. In her work, underlying structure of the copula includes both NPs. Then, NP2 raises to T-head and NP1 to C-head, NP2 bearing the canonical agreement as illustrated in (4). The arrow indicates the operation of Agree.

$$
\text { [CP NP1 [тP NP2 } \mathrm{T} \text { be NP2 NP1] }]^{4}
$$

One other explanation is adopted by Mikkelsen (2005). In this model NP1 moves to structural subject position and T agrees with NP2 since it is the closest available NP in its search domain which is shown in (5).

\section{(5) [ср [тр NP1 $\mathrm{T}$ be NP2 NP1]}

Another approach to explain NP2 agreement pattern abandons the analyses that include inversion as in (4) and (5). These analyses rather propose an agreement pattern which depends on the Match and Agree operations between the $\varphi$-probe that is located on the T-head and the two NPs. Essentially, NP2 agreement arises when NP1 fails to meet the unvalued features in $\varphi$-probe. Béjar \& Kahnemayipour (2017) and Ince et al. (2015) both adopt this approach. This last approach in which agreement pattern is analyzed through probes on T-head rather than inversion of NPs is adopted throughout this paper.

3. The Turkish copula. Although Turkish copula is extensively identified and studied by many researchers (Kornfilt 1996, Kelepir 2008, Aygen 2009, Sağ 2013), studies that account for noncanonical agreement in Turkish are unfortunately very limited. Uzun (2006) first examined the NP2 agreement and concluded that a semantic hierarchy among NPs is responsible for the agreement pattern. Then Ince et al. (2015) built on Uzun's work and provided an account using $\varphi$ probe approach. In this section, I will first introduce the Turkish copula and its properties. After that I will report on canonical and non-canonical agreement patterns in Turkish investigating two previous papers on the matter, Ince et al. (2015) and Uzun (2006).

Kelepir (2001) exemplifies Turkish copula as in (6).
a. Biz genc-Ø-iz. we young-Cop.PRES-1P
'We are young.'
b. Biz hasta-y-dık. we sick-COP.PAST-1P 'We were sick.'

\footnotetext{
${ }^{4}$ Illustrations in (4) and (5) are the excerpts from the work of Béjar \& Kahnemayipour (2017).

${ }^{5}$ Abbreviations in this paper are as follows: $1 \mathrm{~S}=$ first person singular, $1 \mathrm{P}=$ first person plural, $2 \mathrm{~S}=$ second person singular etc., 1SPOSS=first person singular possessive, $1 \mathrm{PPOSS}=$ first person plural possessive $2 \mathrm{SPOSS}=$ second person singular possessive etc., ABL=ablative, ACC=accusative, DAT=dative, GEN=genitive, FUT=future, NMLZR=nominalizer, $\mathrm{PAST}=$ past, $\mathrm{PL}=$ plural, $\mathrm{PROG}=$ progressive, $\mathrm{SG}=$ singular, $\mathrm{SP}=$ specific, you. $\mathrm{P}=$ plural you
} 
The Turkish copula, which we will shortly call COP henceforth, is observed when the predicate is nominal, adjectival or is a participle.

Kelepir (2001) asserts that $-y$ - in (6b) is not a hiatus breaker ${ }^{6}$ but a bound stem that only changes into nothing after a consonant $\left(-y^{\circ}{ }^{\circ} \mathrm{COP}^{9} \rightarrow \varnothing / \mathrm{C}_{-}\right)^{7}$ as a phonological rule. Another piece of evidence is that the COP can be represented as a bound morpheme $i$ -

(7) Biz genç i-di-k.

we young CoP-PAST-1P

'We were young.'

The copula also emerges in some other clitics such as $i$ ken (time adverbial clitic), ise (conditional clitic). Therefore, we will hold that COP will have three allophones: $\varnothing,-y$-, and $i$ -

3.1. COPUla AND CANONICAL AGREEMENT. Canonically, the verbs in Turkish are always in agreement with the subject as seen in (8)

$\begin{array}{llll}\mathrm{O}_{1} & \text { sen- } \mathrm{i}_{2} & \text { bana3 } & \text { gösterdi- } \varnothing / * \text { gösterdi-n/*ä̈sterdi-m. } \\ \text { he } & \text { you-ACC } & \text { I.DAT } & \text { showed-3s/*showed-2s/*showed-1s } \\ \text { 'He showed you to me.' }\end{array}$

göster- 'show' is a 3-place predicate ( $1=$ subject, $2 \& 3=$ internal arguments). Agreeing with any argument other than the subject yields ungrammatical results. As for copular sentences the same holds for the most cases. Uzun (2006) gives the following structure to compare the Turkish copular position to other languages that place copula in different positions. And in (10) he gives examples that follow the structure in (9).

$\begin{array}{lllll}\text { NP1 } & \text { NP2 } & \text { cop } & \text { Turkish } & \\ \text { NP1 } & \text { cop } & \text { NP2 } & \text { English } & \\ \text { cop } & \text { NP1 NP2 } & \text { Irish } & \\ \text { Ali } & \text { doktor idi. } & \text { Turkish } & \text { 'Ali was a doctor.' } \\ \text { John } & \text { is a doctor. } & \text { English } & \\ \text { Is } & \text { é Sean an dochtúir. } & \text { Irish } & \text { 'Sean is a doctor.' }\end{array}$

We have already established that Turkish copula could be null. The variation is not free; however, it is morphosyntactically conditioned: Turkish copula is null in the finite present tense contexts. The full paradigm is given in (11).

\footnotetext{
${ }^{6}$ Kornfilt (1996) states that there is also another kind of -y- in Turkish copular paradigm which is actually a hiatus break. She indicates Turkish present tense copula in 1st person singular and plural includes -y- only in intervocalic contexts (unlike the example (6b), in which the environment is not intervocalic) which is also observed in all vowelinitial suffixes in Turkish.

${ }^{7}$-y-here is orthographic, it is actually a palatal glide [j].
} 

a. Ben doktor-Ø-um.
I doctor-COP-1s
b. Sen doktor-Ø-sun.
you doctor-Cop-2s
c. $\mathrm{O}$ doktor- $\varnothing-\varnothing$.
he/she doctor-COP-3S
d. Biz doktor-Ø-uz.
we doctor-COP-1P
e. $\mathrm{Siz}$ doktor- $\varnothing$-sunuz.
you.P doctor-COP-2P
f. Onlar doktor- $\varnothing$-(lar).
they doctor-COP-3P

3.2. COPULA AND NON-STANDARD AGREEMENT. As observed, there is subject-verb agreement in a Turkish sentence. However, when the predicate is first or second person, unexpectedly it cannot agree with the subject. As (12a) and (13a) show, the agreement on the predicate is with the $1^{\text {st }}$ and $2^{\text {nd }}$ person predicates, respectively.
a. Ali ben-Ø-im.
Ali I-COP-1S
'Ali is me.'
b. *Ali ben-Ø-Ø.
Ali I-COP-3S
a. Ali sen-Ø-sin
Ali you-COP-2S
'Ali is you.'
b. *Ali sen-Ø-Ø
Ali you-COP-3S

The ungrammatical sentences (12b) and (13b) are the expected constructions within the Turkish agreement generalization. However, Ali, the $3^{\text {rd }}$ person subject, fails to agree with the predicate when the predicate is $1^{\text {st }}$ or $2^{\text {nd }}$ person pronominal predicates. The issue is the same with the plural persons as well. $*$ doktor biz- $\varnothing_{C O P}-\varnothing_{3 s}$ and $*$ doktor $\mathrm{siz}-\varnothing_{\mathrm{COP}}-\varnothing_{3 s}$ are still ungrammatical whereas when biz 'we' and siz 'you.P' agree with the predicate, they are grammatical as in doktor biz- $\varnothing_{C O P-i z_{1 p l}}$ doktor siz- $\varnothing_{C O P}$-siniz2pl.

Also note that, if both the subject and the predicate are $1^{\text {st }}$ and $2^{\text {nd }}$ persons, the subject does the agreement. The earliest work that accounts for this non-canonical agreement pattern in Turkish is Uzun's (2006). In his work, Uzun (2006) states that inversion analyses that depend on the distinction of copular clauses cannot properly explain the agreement pattern in Turkish. He finds that rather than distinct copular sentence types causing the different agreement patterns, it is the properties of the two noun phrases in the sentence that designate which NP is going to get the agreement. Before putting his own analysis, he cites Heggie (1988a) who indicated existence of such hierarchy in nominal copular sentences for English.

$$
\text { deixis }>\text { names }>\text { definite descriptors }>\text { indefinites (Heggie 1988a) }
$$

Uzun then proposes the hierarchy shown in (15) for Turkish binominal copular clauses. 
1. $1^{\text {st }}$ and $2^{\text {nd }}$ personal pronouns (ben, sen) $>$

2. Definite specific NPs > (including proper nouns and the 3rd personal pronoun o)

3. Indefinite specific NPs >

4. Definite generic NPs >

5. Indefinite generic NPs

By proposing this, Uzun is able to account for the agreement patterns in (12-13). Ince et al. (2015) builds on this framework and formalizes a $\varphi$-probe analysis in order to account for the syntactic differences between sentences that exhibit NP1 agreement and NP2 agreement.

Ince et al. (2015) propose the explanatory chart in the Figure 1 to summarize the agreement pattern.

(16) NP1 is the nominal subject and NP2 is the nominal predicate.

\begin{tabular}{ccc}
\hline & $\begin{array}{c}\text { person } \\
\text { feature of } \\
\text { DP1 }\end{array}$ & $\begin{array}{c}\text { person } \\
\text { feature of } \\
\text { DP2 }\end{array}$ \\
\hline $\begin{array}{r}\text { agreement } \\
\text { with DP1 }\end{array}$ & 1 or 2 & 1,2 or 3 \\
\hline $\begin{array}{r}\text { agreement } \\
\text { with DP2 }\end{array}$ & 3 & 1 or 2 \\
\hline
\end{tabular}

Figure 1. Agreement patterns chart from Ince et al. (2015)

Ince et al. (2015) also utilize Harley and Ritter's (2002) feature system of personal pronouns. Harley and Ritter's three-way feature system that is used to distinguish personal pronouns is given in (17).

(17) First Person: [referent, participant, speaker]

Second Person: [referent, participant]

Third Person: [referent]

Placing the additional [referent, participant] features under the $\varphi$-probe of the T-head, Ince et al. (2015) state that $\mathrm{T}$ picks the [referent, participant] bearing DP even though it is not the subject. Following scheme from their paper, explains this feature-based agreement. 
NP1 agreement and NP2 agreement scheme respectively, taken from Ince et al. (2015).

\begin{tabular}{|c|c|c|}
\hline$\ldots \varphi \ldots$ & $\mathrm{DP1}(1 / 2) \ldots$ & DP2 $(1 / 2 / 3) \ldots$ \\
\hline $\begin{array}{l}\text { [referent] } \\
\text { [participant] }\end{array}$ & $\begin{array}{l}\text { [referent] } \\
\text { [participant] } \\
\text { ([speaker]) }\end{array}$ & $\begin{array}{l}\text { [referent] } \\
\text { ([participant]) } \\
\text { ([speaker]) }\end{array}$ \\
\hline & \multicolumn{2}{|c|}{$\begin{array}{l}\text { Ben }_{15 \mathrm{G}} \text { Ali-yimim } \\
\text { Sen }_{15 \mathrm{G}} \text { Ali-sin } \\
\sin _{15 \mathrm{G}}\end{array}$} \\
\hline
\end{tabular}

\begin{tabular}{lll}
$\ldots \varphi \ldots$ & DP1 (3) ... & DP2 $(1 / 2) \ldots$ \\
\hline [referent] & [referent] & [referent] \\
[participant] & & $\begin{array}{l}\text { [participant] } \\
\text { ([speaker]) }\end{array}$
\end{tabular}

Ali ben be $_{15 \mathrm{G}}-\mathrm{im}_{1 \mathrm{sG}}$

Ali $\operatorname{sen}_{15 G}-\sin _{15 G}$

Figure 2. Bold text signifies agreement. Agreement pattern chart from Ince et al. (2015). [referent, participant] in the T-head prefers to Agree with the DP that satisfies [referent, participant] features the best.

One point to note here is that some probe situated in the T-head can look into the search domain and Agree with it. This is because Ince et al. do not think that the internal argument makes a phase unlike a $v \mathrm{P}$ for example. Since $v \mathrm{P}$ constitutes a phase, by the time the derivation reaches T-head, $\varphi$-probe cannot agree with the NP2 (the object of the verb) within $v$ P. Instead, they adopt Den Dikken's (2006) Relator Phrase to explain a non-phase element like a small clause within the boundaries of the X-bar theory. This way, $\varphi$-features at T-head can Agree with the predicate.

4. Problems. Before listing problems, it must be pointed out that Ince et al. (2015) restricted their discussion with the equative/identity sentences. Therefore, the problems and solutions listed here will also be restricted by equative sentences ${ }^{8}$. Until here, save for Harley \& Ritter's threeway feature system, I adopt main tenets of their arguments. Main tenets are roughly that there is a hierarchy among personal pronouns and instead of inversion analyses, this hierarchy is responsible for the agreement patterns. Nevertheless, I spotted four cases that are either difficult or impossible to be explained by their explanation. In this chapter, I will list these problems as P1, P2... Next, I will introduce a new feature, [ref], to propose four solutions that go like S1, S2...

\subsection{P1 - THIRD PERSON DP1-DP2 SENTENCES.}

$$
\begin{aligned}
& \text { O Ali-Ø-Ø. } \\
& \text { he Ali-Cop-3s } \\
& \text { 'He is Ali.' }
\end{aligned}
$$

According to the configuration in (18), both the DPs in the example (19) only bear [referent] feature. $\Phi$-probe in Figure 2 states that both [referent] and [participant] sit in the T-head. There are two minor problems with this proposal:

- Ince et al. (2015) do not explain why [participant] is there and [speaker] is not.

- The proposal overgenerates. In all $3^{\text {rd }}$ person DP1-DP2 nominal copular sentences we end up with a feature idly sitting on the T-head.

Here it is important to note that the unvalued [participant] feature is merely an overgeneration, not a cause of Crash. Traditionally, a Crash would be the expectation within minimalist

\footnotetext{
${ }^{8}$ Ince et al. (2015) report that there are only two types of copular sentences have been identified and worked thus far: equative copular sentences and predicational copular sentences. Uzun (2006) also reports the same.
} 
framework. However, they adopt Preminger's (2011) proposal which holds that a probe has to interact with syntactic environment assessing whether there are potential goals, but it does not have to be satisfied.

4.2. P2 - INTRODUCTION OF THE SELF. Most Turkish speakers would mark this sentence ungrammatical:

$$
\begin{aligned}
* \text { Noam } & \text { ben- } \varnothing-\varnothing .^{9} \\
\text { Noam } & \text { I-CoP-3s }
\end{aligned}
$$

However, this sentence is grammatical when you:

- are meeting someone for the first time and introduce your name to the hearer

- call someone on the phone and say who it is on the phone

In these cases where there is an introduction of new information, NP1 should be stressed. When it is stressed NP2 agreement becomes ungrammatical as seen in (21).

$$
\begin{aligned}
& \text { NOAM ben-Ø-Ø/*ben-Ø-im. } \\
& \text { NOAM I-COP-3S/*I-CoP-1s } \\
& \text { 'I am Noam/It's me, Noam.' }
\end{aligned}
$$

Both of these contexts are extremely limited in person, tense and stress. If one changes person \& tense or removes stress from the first NP, the results are ungrammatical.
a. *NOAM
sen-Ø-Ø.
NOAM
you-COP-3s
b. *NOAM
NOAM
ben i-di-Ø-Ø.
c. ${ }^{*}$ Noam
COP-PAST $-3 \mathrm{~s}$
ben-Ø-Ø.
Noam I-COP-3S

In these restricted contexts the sentence (21) is found grammatical by most Turkish speakers. However, NP2 agreement in Figure 2 would block this type of agreement universally since NP2 here has [participant, referent] features while NP1 only has [referent].

4.3. P3 - CONTRASTIVE USE OF PRONOMINAL SUBJECTS. The identity copular sentence (23a) below is ungrammatical while $(23 \mathrm{~b})$ is not. The reason is contrastive focus on the DP kovboy 'cowboy'.
a. *Bu sefer kovboy this time cowboy
siz-Ø-Ø. you.P-COP-3S
b. Bu sefer kovboy this time cowboy siz- $\varnothing-\varnothing, \quad$ haydut biz- $\varnothing-\varnothing$.
you.P-СOP-3s bandit we-COP-3s
'This the cowboy is you.P, the bandit is us.'

Ungrammaticality of (23a) is correctly predicted by the proposal of Ince et al. (2015). According to Figure 2, the agreement should have gone to the second person plural pronoun, but it did not. However, Figure 2 would also rule out (23b) which sounds grammatical.

\footnotetext{
${ }^{9}$ An anonymous reviewer asked whether 3rd person truly exists in Turkish. I believe Turkish has 3rd person. Firstly, Turkish has an optional 3rd person plural marker -1Ar. Second, in genitive-possessive nominal marker and genitive-posssessive nominalized structures 3rd person marker is $-(\mathrm{s}) \mathrm{I}(\mathrm{n})$. This is overt and not optional.
} 
4.4. P4 - NOMINALIZED EMBEDDED STRUCTURES. Nominalization is highly productive embedding strategy in Turkish. In this type of structures, the predicate verb is nominalized with a nominalizer and the structure ends up looking like a genitive-possessive noun phrase. Another important aspect of nominalized embedding is that the Turkish copula COP surfaces as ol- in this kind of structures when the predicate is a nominal.

The observation that demands explanation is that when the NP1 bears the [+GEN] case marker, the predicate agrees with it in a nominalized embedded clause, whereas if there is no [+GEN] on the subject as in (24b), the predicate agrees with NP2, contrary to the predictions of Ince et al. (2015).
a. [Doktor-un ben [doctor-GEN
ol-duğ-un]-u
I COP-NMLZR-3SPOSS]-ACC
biliyor-sun.
'You know that the doctor is me.'
(Genitive is in NP1, so NP1 gets the agreement.)
b. [Doktor
ben ol-duğ-um/*ol-duğ-u]
[doctor I COP-NMLZR-1SPOSS/*COP-NMLZR-3SPOSS]
için
for
sorun yok.
trouble no
'There is no problem since the doctor is me.'
(Genitive is not there, and NP2 gets the agreement.)

The proposal of Ince et al. (2015) therefore comes short explaining the nuance that causes different agreement patterns in these examples.

5. The minimalist proposal, [ref]. ]. Building on Uzun (2006) and Ince et al. (2015), I adopt the basic premises of these papers. Namely,

- Different copular sentence types (equative, predicational etc.) are not responsible for different agreement patterns in Turkish.

- Properties of NPs are responsible for the agreement patterns.

I risk abandoning Harley \& Ritter's (2002) three-way feature system. Albeit it is very useful and elegant, I judge that [ref] is more economical and accurate in explaining nominal copular clauses in Turkish.

[ref] comes in two versions:

- Strong reference: A DP has strong reference if it has contrastive or informative focus in a context. It will be indicated with [ref*].

- Weak reference: Any other DP. It will be indicated with [ref]. ${ }^{10}$

\footnotetext{
${ }^{10}$ An anonymous reviewer criticised stipulative aspect of this proposal. I admit the limitations of my analysis. One of the most noticeable drawbacks, as also pointed out by one of the reviewers, is that these distinct problems look unrelated and explaining all of these via a single feature, [ref*], is too convenient. The inspiration behind my analysis came from Uzun's (2006) semantic hierarchy that put 1st and 2nd personal pronouns to the first place and remainder of the noun phrases (that are syntactically 3rd person) under it. The whole hierarchy has a theme of context-relevantness and distinctness which also has a clear effect on the agreement pattern in the binominal copular clauses. The element I added is that granting a noun phrase a reference strength that is earned in context. I claim that introductory, contrastive and genitive-case contexts only share this property that they make the noun phrase more distinct and relevant in the context. I do not, therefore, put forth this proposal as a separate hypothesis but I do so in order to account for anomalous data found in two papers written in the field: Ince et al. (2015) and Uzun (2006). That said, I am still aware of the fact that this proposal should be improved in the future. Turkish is also a very understudied language in this topic which makes a future contribution much more important.
} 
With this said, I will assume that $1^{\text {st }}$ and $2^{\text {nd }}$ persons will carry [ref*] by their nature, the strength of $3^{\text {rd }}$ person [ref] will be justified by the context.

Under the $\varphi$-features of the T-head, there will sit an uninterpretable reference feature, called [uref]. This feature will be checked by an interpretable referent feature [ref] or [ref*] of one of the DPs in the sentence under c-command relationship.

I am utilizing the search vector at (18) as well, that is the search for agree will start from the subject and then move forward to object.

Hence, if the subject has [ref*] it will Agree with T-head and its $\varphi$-features will determine the agreement on the predicate. If it does not have a [ref*], then the vector will check the NP2 (predicate) for a possible [ref*].

If both DPs have weak reference, [ref], then the subject (i.e., the first stop of the arrow as seen in (18)) agrees with the [uref] of the T-head. The fact that subject's [ref] agrees with the Thead as opposed to the object's T-head is because of the Minimal Link Condition.

This explains the DP1 agreement. In (25) both sentences exhibit DP1 agreement.
a. Sen ben-Ø-sin/*ben-Ø-im. you I-CoP-2s/I-COP-*1s
'You are me.'
b. $\mathbf{O}$ Ahmet- $\varnothing-\varnothing$.
he Ahmet-COP-3s
'He is Ahmet.'

Their agreement pattern is given in (26).

$$
\text { For (25a): } \varphi \overrightarrow{\text { [uref] --- DP1 [ref*] --- DP2 [ref*] }}
$$

b.

For (25b): $\varphi$ [uref] --- DP1 [ref] --- DP2 [ref]

(Bold DPs indicate agreement.)

Remember that search for agree starts from left to right. For (25a) the first stop of the arrow is DP1 which has [ref*] in this case, it is uneconomical to move forward for another potential candidate. For (25b), it is a little more convoluted:

- First the [uref] feature starts probing its goals,

- Finds two candidates: DP1 [ref] and DP2 [ref],

- The Agree-searching arrow starts from the left-hand side, and move rightwards,

- Agree occurs with DP1 [ref], and the search does not move forward since there is not a better (with a strong feature). The not-moving-forward behavior is justified with the Minimal Link Condition.

(26b) is also our S1, that is our solution to P1: When NP1 and NP2 are both $3^{\text {rd }}$ person, $\varphi$-probe Agrees with NP1.

As for our S2, in P2, we gave an example of an extremely limited context of $1^{\text {st }}$ person introducing oneself. While (21) is ungrammatical in normal circumstances, in introduction contexts it gets informative focus and additional stress. When stress added in such a context (21) becomes grammatical. 
In (21) Noam, the proper name, had weak reference [ref], and the first-person nominal predicate had a strong reference [ref*]. Therefore, the Agree-searching arrow must go to the strong reference, i.e., to the first-person nominal predicate. However, the introductory context described above earns Noam's reference strength making it into a [ref*]. (27) illustrates the agreement operation.

$$
\varphi[\text { uref] --- DP1 [ref*] --- DP2 [ref*] }
$$

The agreement vector stops at DP1 as per Minimal Link Condition.

S3 is very similar: Contrastive context earns a DP strength. In (23a) DP1 lacks contrastive focus, or any other reason to enhance its feature strength. Since DP2 is a nominal with [ref*], the Agree-searching arrow selects it. If we have contrastive focus on DP1 as in (28b), however, the DP1 must Agree with the copula since it has [ref*] in this context.

$$
\begin{array}{rlll}
\text { a. Bu } & \text { sefer } & \text { kovboy } & \text { siz- } Ø-\text {-siniz/*siz- } Ø-[3 \mathrm{~s}] . \\
\text { this } & \text { time } & \text { cowboy } & \text { you.P-COP-2P/*you.P-COP-3s }
\end{array}
$$

'This time cowboys are you.'

$$
\varphi \text { [uref] DP1 [ref] DP2 [ref*] }
$$

b. Bu sefer kovboy siz-Ø-Ø, haydut biz- $\varnothing-\varnothing$. this time cowboy you.P-cop-3s, bandit we-CoP-3s

'This time cowboy are you (plural), the bandits are us.'

$$
\varphi \text { [uref] DP1 [ref*] DP2 [ref*] }
$$

As for $\mathrm{S} 4$, the answer is as one may predict at this point: $[+\mathrm{GEN}]$ earns a DP strong reference. Nevertheless, it is hard to defend that a genitive case increases focus or earns stress to a noun phrase. However, there is an interesting parallelism between the embedded genitive-possessive clauses in (24) and semantic content of [+GEN] in noun phrases. (29) exemplifies this role of genitive case in Turkish.
a. şehir 1şıklar-1 city lights-3sPoss 'city lights'
b. şehr-in 1şılar-1 city-GEN lights-3sPoss 'lights of the city'

[+GEN] DP in (39b) is definite and specific whereas [-GEN] DP in (29a) is generic and unspecific. Although this is a bit different from other focus-based reference strengthening, I argue that it still holds and as such explains the data as shown in (30). 
a. [Doktor-un ben ol-duğ-un]-u biliyor-sun. [doctor-GEN I COP-NMLZR-3sPoss]-ACC know-2s

'You know that the doctor is me.'

$\varphi[$ uref] NP1 [ref*] NP2 [ref*]

b. [Doktor ben ol-duğ-um/*ol-duğ-u] için sorun yok.

[doctor I COP-NMLZR-1SPOSS/*COP-NMLZR-3SPOSS]for trouble no

'There is no problem since the doctor is me.'

$\varphi$ [uref] NP1 [ref] NP2 [ref*]

In (30a), genitive in NP1 earns that DP [ref*], so the $\varphi$-probe Agrees with it as per Minimal Link Condition. In (30b) the embedded subject lacks genitive case hence it has weak [ref], so the Agree happens with the NP2 which is the $1^{\text {st }}$ person pronominal predicate.

One potential limitation of this proposal is abandoning Harley and Ritter (2002) features. Although by abandoning it I could develop a more economical feature system, it is still a risk since this paper has a very wide usage in the literature. Because of these limitations I include an alternative analysis based on the detailed work of Béjar \& Kahnemayipour (2017) which could be fruitful for future work.

6. An alternative analysis: Béjar \& Kahnemayipour's model. One of the most important analyses that adopts $\varphi$-probe approach rather than inversion in binominal copular clauses is Béjar \& Kahnemayipour (2017). They analyzed two languages, Eastern Armenian and Persian. These languages show striking similarities and some differences with Turkish. Thus, a comparison between these languages and Turkish might be illuminating for future work and also beneficial to see where Turkish copular sentence stands typologically.

They mention three major types of copular clauses: predicational, specificational and equative. And propose distinct morphosyntactic configurations for different copular constructions.

As noted earlier, Béjar \& Kahnemayipour (2017) abandon the analyses that include inversion. Similar to Ince et al. (2015), they propose that NP2 agreement arises when featural components NP1 is defective relative to the $\varphi$-probe that sits on T-head. The general scheme could be illustrated as follows:

$$
\ldots \mathrm{T}_{\mathrm{AGR} \_\varphi} \ldots \mathrm{NP} 1_{\varphi} \ldots \mathrm{NP} 2_{\varphi} \quad \text { (Béjar } \& \text { Kahnemayipour (53)) }
$$

They also adopt Harley \& Ritter's (2002) [participant] and [speaker] features. They also propose new features: deictic feature [d] and a minimal nominal feature [n]. The former identifies all deictic NPs as a natural class while the latter is required in the syntax so that nominal category is recognized. In short, all nouns have [n] and all deictic nouns have [d].

Crucially, they argue that since intensional expressions, for example NP1s (subjects) in specificational copular clauses, lack extensional reading they cannot be deictic and cannot contain $[\mathrm{d}] .^{11}$

\footnotetext{
11 The argument that subject in specificationals cannot be intensional, therefore cannot be used deictically comes from the fact that intensional NP is concealed deep within CP. In that they follow Romero (2005), Heycock (2012) and Den Dikken (2006) and provide following DP structure that contains a defective D-head:

- Context: a scenario where detective Poirot finds the murderer after investigation.
} 
By giving numerous examples, they find that Persian consistently exhibits NP1 agreement in assumed identity contexts, regardless of the features of NP1 and NP2. They illustrate this pattern of Persian as follows:

(32) In Persian assumed identity (a form of equative), the unvalued features [_n] and [_d] sits on AGR and valued at NP1 at any case. NP1 is guaranteed to bear at least [n, d] which perfectly satisfy $\varphi$-features on AGR.

Assumed identity context in Persian

\begin{tabular}{|c|c|c|}
\hline AGR & NP1(3) . & NP2 $(1 / 2 / 3) \ldots$ \\
\hline$\left[\_n\right]$ & {$[n]$} & {$[n]$} \\
\hline$\left[\_d\right]$ & {$[d]$} & $\begin{array}{l}{[d]} \\
\text { ([part]) } \\
\text { ([spkr]) }\end{array}$ \\
\hline
\end{tabular}

Béjar \& Kahnemayipour, 2017, (59)

Persian specificational sentences, on the other hand consistently exhibit NP2 agreement pattern:

(33) [_n] and [_d] on the AGR fail to Match and Agree with NP1 since it lacks the feature [d]. In order to be satisfied, Agree occurs with NP2.

Specificational context in Persian

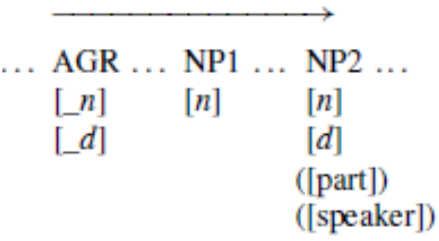

Béjar \& Kahnemayipour, 2017, (58)

Eastern Armenian is analyzed to have [participant] feature on AGR. It exhibits [participant]sensitive behavior in assumed identity context. However, in specificational sentences it is very similar to the scheme of Persian:

(34) The features on AGR fail to find a Match in NP1, therefore proceed to Agree with NP2. If both NPs lack [participant], i.e. 3rd person [participant] feature finds no Match. In that case, Béjar \& Kahnemayipour (2017) utilizes a process called Probe Reduction which impoverishes the feature bundle from bottom if a feature fails to Agree in one cycle in derivation.

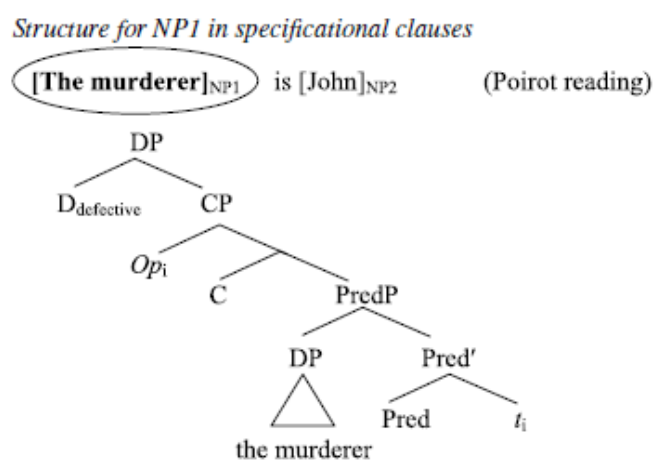

. (Béjar \& Kahnemayipour, 2017 example (57)): 


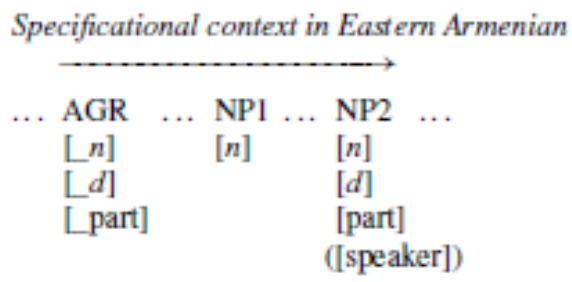

Béjar \& Kahnemayipour, 2017, footnote [30]

(35) For assumed identity contexts Eastern Armenian is [participant]-sensitive, i.e. probe at AGR finds a Match on the first NP that includes [participant]. If neither has [participant] gets eliminated by Probe Reduction and [_n, _d] Agrees with $3^{\text {rd }}$ NP1 person that possesses [n, d]

I have found that Eastern Armenian variant ${ }^{12}$ of the equative scheme successfully explains many equative sentences on this paper:

(36) [_n,_d,_participant] sits on AGR.

- For NP1(3)-NP2(3) sentences, process is as in (35). This explains the data in (19).

- For NP1(1/2)-NP2(1/2) sentences, the probe on AGR finds first compatible Match with NP1. This explains the data on (25a).

- For NP1(3)-NP2(1/2) sentences, probing starts from AGR and fails to Agree with NP1 since it lacks [participant]. Instead, it Agrees with NP2. This explains the data in (12a, 13a, 28a, 30b).

That said, I have not discovered how $3^{\text {rd }}$ person plural agreement pattern in Turkish copular sentences can be represented in specificational sentences. Recall that in their paper, specificational sentences argued to exhibit NP2 agreement. Both Eastern Armenian and Persian are analyzed that way. But Turkish $3^{\text {rd }}$ person plural agreement marker, $-l A r$, is optional but may only occur when $3^{\text {rd }}$ person subject is plural. Following example from Béjar \& Kahnemayipour (2017) is grammatical in Eastern Armenian as in (37) (Persian is the same in that regard) but it is ungrammatical in Turkish as in (38). The only way to make it grammatical is to make agreement singular like NP1.

\footnotetext{
12 The reason why I think Eastern Armenian pattern is closer Turkish is that Turkish assumed identity sentences do not exhibit a strict NP1 agreement pattern like Persian. For example, the agreement pattern in the Persian assumed identity sentences in the following is impossible for Turkish (example numbers are copied from their paper):

(13b) qaatel to- $\varnothing$-e. (assumed identity reading) murderer you-be-3s

'The murderer is you.'

In Turkish: *Katil sen-Ø-Ø. murderer you-be-3s

(14b) Sabah man-Ø-e. (assumed identity reading) Sabah I-be-3s

'Sabah is me.'

In Turkish: *Sabah $\quad$ ben- $\varnothing-\varnothing$. murderer I-be-3s

However, Eastern Armenian assumed identity sentences are participant-sensitive just like the ones in Turkish. Therefore, I hold that Turkish AGR bears [_participant] feature, similar to Eastern Armenian.
} 


$\begin{array}{lllll}\text { iskakan } & \text { problem-ə } & \text { heqapoxutyan } & \text { metz-er-ən } & \text { en. } \\ \text { main } & \text { problem-SP } & \text { revolution.GEN } & \text { chief-PL-SP } & \text { are }\end{array}$

'The main problem is the leaders of the revolution.'

Esas problem devrim-in lider-leri- $\varnothing-\varnothing / *$ lider-leri- $\varnothing$-ler.

main problem revolution-GEN leader-3PPoss-CoP-3s/*leader-3PPoss-CoP-3P.

Although at this moment I could not find a way within this analysis to account for the problems I laid out above as P1, P2..., this account by Béjar \& Kahnemayipour is superior to minimalist account in many regards. First, it has a clearly defined feature system consisting of Harley \& Ritter (2002) features, [d] and [n]. Moreover, it is able to explain the data across multiple copular sentence types whereas this paper mainly focused on equative copular structures.

In this section I utilized a detailed account by Béjar \& Kahnemayipour (2017) and tried to investigate Turkish copular sentences within it in order to be beneficial to potential future work on copular sentences in Turkish. The findings here are by no means conclusive and need detailed work by more researchers.

7. Conclusion. Turkish has a solid subject-verb agreement system. When there is a vP layer, there is no way but agreeing with the subject. When vP is lacking though (i.e., it is copular sentence) the agreement becomes a little tricky. When the predicate is first or second person, they dominate the agreement if the subject is $3^{\text {rd }}$ person. Although Ince et al. (2015) do a great job accounting for this phenomenon by using Harley \& Ritter's (2002) feature system, I think a single feature called [ref] has more economical and has more explanatory power. With strong ([ref*]) and weak ([ref]) versions, I tried to account for all that had been accounted before by Ince et al. (2015) and I tried to explain 4 new contexts in which their explanation comes short:

- Nominal copular sentences in which both DP1 and DP2 is $3^{\text {rd }}$ person

- Introduction of the self

- Contrastive use in assumed identity contexts

- Embedded nominalized structures

I also compared and contrasted my data in a more recent and fine-grained account by Béjar \& Kahnemayipour (2017). Its feature system greatly analyzes Turkish copular sentences. However, in this paper we barely scratched the surface of analyzing various aspects of Turkish copular sentences. Many future works should illuminate our way before we state a definitive conclusion in this matter. 


\section{References}

Aygen, G. (2009). How many manifestations of the "copula" can a language employ? Journal of Linguistics and Literature 6.2, 15-30.

Béjar, Susana. 2003. Phi-syntax: a theory of agreement. Toronto: University of Toronto dissertation

Béjar, Susana \& Kahnemuyipour, Arsalan. 2017. Non-canonical agreement in copular clauses. Journal of Linguistics 53.3, 463-499.

Chomsky, Noam. 2000. Minimalist inquiries: The framework. Cambridge, Mass.: MIT Press.

Den Dikken, Marcel. 2006. Relators and linkers: the syntax of predication, predicate inversion, and copulas. Cambridge, Mass.: MIT Press.

Harley, Heidi \& Ritter, Elizabeth. 2002. Person and number in pronouns: a feature-geometric analysis. Language 78.3, 482-526.

Heggie, Lorie. 1988a. The syntax of copular structures. Ph.D. dissertation, University of Southern California.

Heggie, Lorie. 1988b. A unified approach to copular sentences In H. Borer (Ed.), Proceedings of WCCFL 7:129-142. Stanford, CA: Stanford Linguistics Association.

Heycock, Caroline. 2012. Specification, equation and agreement in copular sentences. Canadian Journal of Linguistics 57.2, 209-240.

Higgins, Roger F. 1973. The pseudo-cleft construction in English. Ph.D. dissertation, MIT.

Higgins, Roger F. 1979. The pseudo-cleft construction in English. New York: Garland.

Ince, Atakan, Aygen, Gülşat \& Aydın, Özgür. 2015. Copular structures as (non)phases. Ankara Papers in Turkish and Turkic Linguistics. 87-97.

Kelepir, Meltem. 2001. Topics in Turkish syntax: clausal structure and scope. Ph.D. dissertation, MIT.

Kelepir, Meltem. 2008. Copular forms in Turkish, Noghay and Turkmen. MITWPL, 54, 83- 100, Cambridge: MA.

Kornfilt, Jaklin. 1996. On copular clitic forms in Turkish. In A. Alexiadou, N. Fuhrhop, P. Law and S. Loehken (eds.), ZAS Papers in Linguistics. Berlin: Zentrum für Allgemeine Sprachwissenschaft, Vol 6, 96-114.

Mikkelsen, Line. 2005. Copular clauses: Specification, predication and equation. Amsterdam \& Philadelphia, PA: John Benjamins.

Partee, Barbara H. 1987. Noun phrase interpretation and type-shifting principles. In J. Groenendijk, D. de Jong, and M. Stokhof (Eds.), Studies in discourse representation theory and the theory of generalized quantifiers. 115-143. Dordrect: Foris.

Preminger, Omer. 2011. Agreement as a Fallible Operation. Ph.D. dissertation, MIT.

Romero, Maribel. 2005. Concealed questions and specificational subjects. Linguistics and Philosophy 28, 687-737.

Sağ, Yağmur. 2013. Copula in Turkish. In: MWPL 67: Proceedings of the 8th Workshop on Altaic Formal Linguistics (WAFL 8).

Uzun, Nadir Engin. 2006. A hierarchical explanation against the distinction of nominal copular sentences in Turkish. Turkic Languages 10, 111-130.

Williams, Edwin. 1983. Williams, E. (1983). Semantic vs. syntactic categories. Linguistics and philosophy 6,3. 423-446. 